\title{
PROSES KEGIATAN PENGHIMPUNAN DAN DISTRIBUSI WAKAF TUNAI DI BAITUL MAAL HIDAYATULLAH SURABAYA'
}

\author{
Muhammad Afdhal \\ Program Studi S1 Ekonomi Islam-Fakultas Ekonomi dan Bisnis-Universitas Airlangga \\ Email : afdalm24@gmail.com \\ Siti Inayatul Faizah \\ Departemen Ekonomi Syariah-Fakultas Ekonomi dan Bisnis-Unversitas Airlangga \\ Email : inay.hakim@gmail.com
}

\begin{abstract}
:
This research adopts a qualitative approach with case study methodology. Data collection is done through carrying out interview with informants such as branch manager, financial manager, marketing staffs and several donators of Baitul Maal Hidayatullah. Secondary data comes under the form of documents pertaining to the practice performed by Baitul Maal Hidayatullah. The pattern matching technique is then used to compare patterns based on empirics with the predicted patterns. Cash waqf funds are collected through direct and indirect means. The collection of cash waqf funds by Baitul Maal Hidayatullah are in accordance with the procedures set out by Badan Wakaf Indonesia which are, analysis of needs, waqif profile identification, the product of waqf, and the transactional cost. The distribution of cash waqf funds by Baitul Maal Hidayatullah are in accordance with what has been ordained by the Direktorat Pemberdayaan Wakaf, which includes, waqf distribution for education and social services.
\end{abstract}

Keywords: Collection, Distribution, Cash Waqf, Baitul Maal Hidayatullah

\section{PENDAHULUAN}

Ekonomi Islam di Indonesia semakin tumbuh dan berkembang membuat masyarakat ikut berperan aktif dalam perkembangan ekonomi Islam baik melalui sektor moneter dan sektor riil ataupun hanya sekedar mempelajari dasar - dasar tentang ekonomi Islam.

Dalam sistem ekonomi Islam terdapat mekanisme ekonomi dan mekanisme non ekonomi dimana mekanisme ekonomi adalah mekanisme untuk mengurangi krisis melalui kegiatan ekonomi yang sifatnya produktif, sedangkan mekanisme non ekonomi adalah mekanisme dalam pemberantasan krisis selain melalui kegiatan ekonomi agar terjadi keseimbangan harta didalam masyarakat

(Aditya, 2008:92-93). Mengurangi krisis bisa dalam artian mengurangi kemiskinan dan di Indonesia sendiri angka kemiskinan walaupun menurun tetapi tetap memerlukan peran aktif masyarakat dan pemerintah untuk lebih menekan angka kemiskinan di Indonesia. Masih banyak penduduk Indonesia yang terjerat dalam kemiskinan.

Badan Pusat Statistik (BPS) mencatat pada tahun 2014 jumlah penduduk miskin Indonesia di kota adalah 10,36 juta jiwa, sementara di desa lebih banyak yaitu 17,37 juta jiwa.Prosentase penduduk miskin tahun 2013 di kota dan desa masing masing $8,52 \%$ dan $14,42 \%$ turun menjadi $8,16 \%$ dan $13,76 \%$ pada tahun 2014 . Islam

1) Jurnal ini merupakan bagian dari skripsi dari Muhammad Afdhal, NIM : 041114099 , yang diuji pada 11 Februari 2016 
Afdhal, et al/Jurnal Ekonomi Syariah Teori dan Terapan Vol. 3 No. 6 Juni 2016: 490-503; PROSES KEGIATAN PENGHIMPUNAN DAN DISTRIBUSI WAKAF TUNAI DI BAITUL MAAL HIDAYATULLAH SURABAYA

sebagai agama yang memberikan rahmat bagi semua makhluk, sehingga dari makna tersebut dapat diartikan bahwa Islam sangat peduli terhadap kehidupan kaum dhuafa. Sebagai bentuk kepedulian Islam terhadap kaum tidak berpunya, Islam menghadirkan lembaga zakat, infak, sedekah, dan wakaf yang berfungsi untuk mengumpulkan dan melakukan pendistribusikan kepada masyarakat, sehingga dapat meningkatkan kesejahteran masyarakat.

"Keberadaan lembaga Zakat, Infak, Sedekah dan Wakaf (ZISWAF) masih dipandang sebagai cara yang paling efektif untuk mendapatkan surga sehingga orientasi ZISWAF sebagai sarana untuk memberikan kesejahteraan dan memberdayakan umat masih belum terwujud" (Hidayat, 2010:312).

Azizy (2004:122) menjelaskan Wakaf merupakan salah satu bentuk ibadah, yang nilainya lebih dominan pada ibadah sosial. Wakaf bertujuan untuk memberikan manfaat atau faedah harta yang diwakafkan kepada orang yang berhak menerima dan digunakan sesuai dengan ajaran syariah Islam. Hal ini mengacu pada fungsi wakaf yang disebutkan di pasal 5 UU no.41 tahun 2004 yang menyatakan wakaf berfungsi untuk mewujudkan potensi dan manfaat ekonomis harta benda wakaf selain untuk kepentingan ibadah juga untuk memajukan kesejahteraan umum. Wakaf yang populer saat ini adalah wakaf uang atau bisa juga disebut wakaf tunai, Majelis Ulama Indonesia pada tanggal 11 Mei 2002 mengeluarkan fatwa yang membolehkan wakaf uang (cash wakaf/waqf al nuqud) dengan syarat nilai pokok wakaf harus dijamin kelestariannya.

Nasution (2005:43-44) melakukan asumsi bahwa jumlah penduduk Muslim kelas menengah di Indonesia sebanyak 10 juta jiwa dengan rata-rata penghasilan perbulan antara Rp 500.000,00 (lima ratus ribu rupiah) - Rp 10.000.000,00 (sepuluh juta rupiah) maka dana wakaf terkumpul selama satu tahun sejumlah Rp3.000.000.000.000. Baitul Maal Hidayatullah sebagai lembaga amil zakat yang mempunyai program dalam penyaluran dana wakaf tunai akan dilihat proses penghimpunan dan cara pendistribusian dana wakaf tunai apakah sudah dilakukan sesuai dengan teori yang akan dijelaskan di landasan teori.

\section{LANDASAN TEORI}

Norton (2002:15) menjelaskan bahwa menghimpun dana merupakan sebuah proses menggalang dana bukan sekedar meminta uang akan tetapi menjual ide dan meyakinkan pemberi, bahwa memberi bantuan kepada orang yang membutuhkan akan dapat memberikan perubahan kepada masyarakat, dengan demikian pemberi akan menerima ide tersebut dan mau menyumbangkan sebagian hartanya untuk kepentingan masyarakat luas. Dari hasil penghimpunan itu pengelola dana mempunyai tanggung jawab penuh sehingga pemilik dana tidak boleh turut serta dalam mengelola dana, karena itu yang mengetahui hasil dari usaha penghimpunan dana adalah 
Afdhal, et al/Jurnal Ekonomi Syariah Teori dan Terapan Vol. 3 No. 6 Juni 2016: 490-503; PROSES KEGIATAN PENGHIMPUNAN DAN DISTRIBUSI WAKAF TUNAI DI BAITUL MAAL HIDAYATULLAH SURABAYA

penghimpun atau yang dikenal dengan fund-raiser (Wiroso, 2005:19). Secara umum penghimpunan dana diartikan sebagai aktivitas perencanaan, pelaksanaan dan pengendalian terhadap dana yang diperoleh dari masyarakat (Zulkifli, 2003:93).

Dua prinsip penting dalam pengelolaan harta kekayaan menurut Islam sesuai dengan Al-Quran, antara lain

1. Larangan mencintai harta secara berlebihan, hal ini sesuai dengan firman Allah Swt dalam surat Al Fajr ayat 20 yaitu

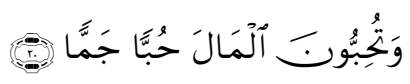

Artinya:

"dan kamu mencintai harta dengan kecintaan yang berlebihan" (Q.S 89:20 Kementrian Agama Rl, 2010:593).

Maksud dari ayat diatas yakni dilarang mencintai harta secara berlebih - lebihan. Sebagian yang lain menambahkan, secara keji (Katsir, 2001:468)

2. Larangan Mencampur - adukkan yang halal dan batil, hal ini sesuai dengan surat Al Fajr ayat 19:

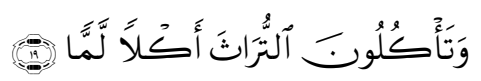

Artinya:

"sedangkan kamu memakan harta warisan dengan cara mencampurbaurkan (yang halal dan haram)" (Q.S 89:19 Kementrian Agama Rl, 2010:593)

Maksud dari ayat diatas yakni berasal dari mana pun harta itu diperoleh, baik dari yang halal maupun yang haram (Katsir, 2001:468).

Metode yang dimaksud disini adalah suatu bentuk kegiatan khas yang dilakukan oleh sebuah organisasi dalam rangka menghimpun dana dari masyarakat (Wiroso, 2005:137).

Metode dalam menghimpun dana dapat dibagi pada dua jenis, yaitu metode penghimpunan langsung dan metode penghimpunan tidak langsung. Di bawah ini diuraikan mengenai penjelasan masing - masing metode tersebut, yaitu:

a. Metode Penghimpunan Langsung

Metode ini merupakan perjanjian atas suatu jenis dimana pihak pertama menyediakan dana dan pihak kedua bertanggung jawab atas pengelolaan (Wiroso, 2005:33). Metode ini adalah metode yang menggunakan teknik atau cara yang melibatkan partisipasi waqif secara langsung, yaitu bentuk bentuk penghimpunan dimana proses interaksi dan daya akomodasi terhadap respon waqif bisa seketika langsung dilakukan (Wiroso, 2005:134).

b. Metode Penghimpunan Tidak Langsung

Metode ini diartikan sebagai titipan dari satu pihak kepada pihak lain (Wiroso, 2005:20). Suatu metode yang menggunakan teknik - teknik atau cara - cara yang tidak melibatkan partisipasi waqif secara langsung, yaitu bentuk bentuk penghimpunan dana dimana tidak dilakukan dengan memberikan daya akomodasi langsung terhadap respon waqif seketika. Contoh dari metode ini adalah melalui iklan, penyelenggaraan acara, melalui perantara, menjalin relasi, melalui referensi dan mediasi. 
Afdhal, et al/Jurnal Ekonomi Syariah Teori dan Terapan Vol. 3 No. 6 Juni 2016: 490-503; PROSES KEGIATAN PENGHIMPUNAN DAN DISTRIBUSI WAKAF TUNAI DI BAITUL MAAL HIDAYATULLAH SURABAYA

Pada umumnya sebuah lembaga melakukan kedua metode penghimpunan dana tersebut, karena keduanya memiliki kelebihan serta tujuannya sendiri. Metode langsung sangat diperlukan karena tanpa metode langsung, waqif akan kesulitan mendonasikan dananya. Sedangkan jika semua bentuk penghimpunan dilakukan secara langsung, akan menjadi kaku dan tidak fleksibel, oleh karena itu semua lembaga harus pandai - pandai mengkombinasikan metode tersebut.

Penghimpunan dana dalam penelitian ini adalah proses mempengaruhi masyarakat untuk berwakaf dan Badan Wakaf Indonesia (BWI) menjelaskan dalam pelaksanaannya meliputi unsur- unsur berikut: Analisis kebutuhan, segmentasi, identifikasi profil waqif, produk, harga biaya transaksi dan promosi. Berikut penjelasan atas unsur - unsur penghimpunan tersebut:

a. Analisa Kebutuhan

Analisis kebutuhan meliputi kesesuaian dengan syariat, laporan dan pertanggung jawaban, manfaat bagi kesejahteraan umat, pelayanan yang berkualitas, silaturahmi dan komunikasi.

b. Segmentasi

Segmentasi waqif sesuai undangundang adalah perorangan, organisasi, dan lembaga berbadan hukum. Tetapi dilihat dari sudut pandang geografis juga dapat dilakukan misalnya dengan segmentasi lokal, regional, nasional dan internasional. Dilihat dari sudut pandang demografis misalnya jenis kelamin, kelompok usia, status perkawinan, dan ukuran keluarga. Selanjutnya secara psikologis misalnya status ekonomi, pekerjaan, gaya hidup, hobi dan yang lain.

c. Identifikasi Profil Donatur/calon waqif Hal ini sangat penting untuk mengetahui profil calon waqif serta biaya operasional harta benda wakaf. Profil biodata waqif perorangan dapat berbentuk biodata atau CV, untuk calon waqif organisasi atau lembaga hukum dalam bentuk company profile lembaga.

d. Produk

Nazhir seharusnya mempunyai satu atau beberapa produk wakaf sesuai perundangan yang akan ditawarkan kepada para calon waqif. Produk wakaf yang ditawarkan nantinya diharapkan mampu menarik simpati dari para calon waqif agar mau berdonasi di lembaga tersebut.

e. Harga

Harga yang dimaksud adalah besaran nilai harta benda wakaf yang akan diwakafkan atau kemampuan nazhir untuk mengelolanya. Misalnya untuk Badan Wakaf Indonesia (BWI) sebagai nazhir, dalam wakaf tunai dengan Lembaga Keuangan Syariah (LKS) di empat Bank Syariah telah disepakati minimal dengan harga atau nilai dua ratus lima puluh ribu rupiah sampai satu 
Afdhal, et al/Jurnal Ekonomi Syariah Teori dan Terapan Vol. 3 No. 6 Juni 2016: 490-503; PROSES KEGIATAN PENGHIMPUNAN DAN DISTRIBUSI WAKAF TUNAI DI BAITUL MAAL HIDAYATULLAH SURABAYA

juta rupiah dan seterusnya, calon waqif dapat melaksanakan ikrar wakaf uang.

Pendistribusian berasal dari kata dasar distribusi yang berarti penyaluran (pembagian, pengiriman) kepada beberapa orang atau ke beberapa tempat. Sedangkan menurut Kamus Besar Bahasa Indonesia pendistribusian mempunyai arti proses, cara, perbuatan mendistribusikan. Hidayat (2010:244) menjelaskan bahwa ada tiga aktivitas ekonomi yang disepakati oleh para ekononom, yakni produksi, distribusi dan konsumsi. Dua aktivitas pertama kemudian dijabarkan dengan pertanyaan; what to produce, how to produce dan for whom to produce. What and how berkaitan dengan materi dan proses teknis produksi, sedangkan for whom menjadi acuan target distribusi.

Distribusi merupakan faktor yang tidak dapat dipisahkan dari sistem ekonomi karena dengan distribusi yang baik dapat tercipta keadilan sosial dalam bidang ekonomi dari proses distribusi inilah semua kebutuhan masyarakat dapat terpenuhi, akan tetapi pada proses ini pula banyak terjadi penyalahgunaan wewenang dan sebagainya sehingga faktor ekonomi tersebut tidak merata atau tepat sasaran. Fungsi distribusi dilakukan oleh badan usaha atau perorangan sejak pengumpulan barang dengan jalan membelinya dari produsen untuk disalurkan kepada konsumen.

Dana wakaf harus didistribusikan tentunya dengan mengikuti petunjuk dari
Allah Swt, karena harta itu diciptakan Allah yaitu untuk menunjang manusia. Petunjuk dari Allah Swt tentang pendistribusian dan pemanfaatan harta menurut Ghazaly, et.al. (2010: 27) sebagai berikut:

1. Harta digunakan untuk kepentingan kebutuhan hidup sendiri. Penggunaan harta untuk kebutuhan hidup dinyatakan oleh Allah Swt dalam surat $\mathrm{Al}$ - Mursalat ayat 43:

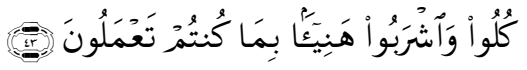

Artinya:

"dikatakan kepada mereka makan dan minumlah kamu dengan enak karena apa yang telah kamu kerjakan" (Q.S 77:43 Kementrian Agama Rl, 2010:580)

Yakni, hal tersebut dikatakan kepada mereka sebagai bentuk kebaikan kepada mereka (Katsir, 2001: 245)

2. Harta digunakan untuk memenuhi kewajibannya kepada Allah Swt. Kewajiban kepada Allah itu ada dua macam, yang pertama adalah kewajiban materi yang berkenaan dengan kewajiban agama yang merupakan utang terhadap Allah, seperti membayar zakat atau dalam kasus ini wakaf tunai. Kedua, kewajiban materi yang harus ditunaikan untuk keluarga, yaitu istri, anak, dan kerabat (Ghazaly, et. al, 2010:29).

Masyarakat Indonesia selama ini memiliki pemahaman bahwa penyaluran harta benda wakaf hanya untuk keperluan ibadah saja seperti membangun masjid, pondok pesantren, dan keperluan ibadah lain. Pemahaman 
Afdhal, et al/Jurnal Ekonomi Syariah Teori dan Terapan Vol. 3 No. 6 Juni 2016: 490-503; PROSES KEGIATAN PENGHIMPUNAN DAN DISTRIBUSI WAKAF TUNAI DI BAITUL MAAL HIDAYATULLAH SURABAYA

seperti itu harus ditinggalkan karena nyatanya wakaf dapat dimanfaatkan untuk kepentingan sosial yang lebih luas dan menyeluruh, seperti bidang pendidikan, kesehatan, pelayanan sosial, dan pengembangan ekonomi melalui pemberdayaan usaha kecil dan menengah (DPW, 2006:72). Berikut ini diuraikan secara singkat beberapa bidang yang dapat dikembangkan agar masyarakat dapat merasakan kesejahteraan yang diinginkan dari pemanfaatan wakaf:

a) Bidang Pendidikan

Pengembangan dalam bidang pendidikan dapat berupa pembangunan pesantren, madrasah, perguruan tinggi Islam, lembaga riset untuk masyarakat, dan perpustakaan. Kemudian dalam hal pemberdayaan dan pengembangan kurikulum, sumber daya manusia, dan proyek-proyek riset teknologi tepat guna.

b) Bidang Kesehatan

Kendala yang dihadapi masyarakat yang kurang mampu salah satunya adalah sulitnya mendapatkan penanganan kesehatan yang memadai di rumah sakit dikarenakan kekurangan biaya, untuk itu pengembangan dalam bidang kesehatan akan sangat membantu mereka yang membutuhkan. Pembangunan rumah sakit, poliklinik, apotik, dan alat-alat medis, serta pemberdayaan dan pengembangan SDM kesehatan dari dana wakaf akan meringankan beban pemerintah dalam bidang kesehatan.

c) Bidang Pelayanan Sosial

Dana wakaf terutama wakaf tunai akan membantu dalam pembangunan bidang pelayanan sosial untuk pembangunan fasilitas umum yang lebih memadai, tempat-tempat ibadah, dan lembaga keagamaan yang representatif, lalu pemberdayaan kaum dhuafa melalui berbagai pelatihan, dan membuat berbagai proyek dakwah yang mencakup beberapa bidang.

d) Bidang Pengembangan UKM

Usaha Kecil dan Menengah (UKM) yang berkembang akan membuat UKM mampu meningkatkan daya saing produknya dan bukan tidak mungkin akan dapat menjangkau pasar luar negeri. Untuk itu perlu dilakukan hal hal seperti memprioritaskan pembinaan dan pengembangan UKM yang menggunakan bahan baku dari sumber daya alam dan industri pendukungnya untuk pasar dalam dan luar negeri, seperti agro industri, kerajinan keramik, dan gerabah. Selanjutnya dalam kaitannya dengan wakaf tunai adalah memberi peluang lebih besar kepada lembaga dan Nazhir wakaf tunai untuk berpartisipasi aktif dalam menyediakan fasilitas permodalan bagi UKM. Membantu pemasaran dan promosi UKM dan pembangunan infrastruktur yang mendukung pemberdayaan ekonomi 
Afdhal, et al/Jurnal Ekonomi Syariah Teori dan Terapan Vol. 3 No. 6 Juni 2016: 490-503; PROSES KEGIATAN PENGHIMPUNAN DAN DISTRIBUSI WAKAF TUNAI DI BAITUL MAAL HIDAYATULLAH SURABAYA

rakyat juga bisa dilakukan dengan memanfaatkan dana wakaf tunai yang ada. Sehingga masyarakat bisa lebih paham bahwa tidak hanya dana zakat saja yang bisa diberdayakan.

Wakaf tunai merupakan wakaf yang dikeluarkan oleh seseorang, kelompok orang, atau suatu lembaga dalam bentuk vang. Majelis Ulama Indonesia pada tanggal 11 Mei 2002 mengeluarkan fatwa yang membolehkan wakaf uang (cash wakaf/waqf al nuqud) dengan syarat nilai pokok wakaf harus dijamin kelestariannya. Wakaf uang atau juga bisa disebut wakaf tunai menurut Majelis Ulama Indonesia adalah wakaf yang dilakukan seseorang, kelompok orang, lembaga atau badan hukum dalam bentuk uang tunai.

Mavquf'alaih adalah pihak yang ditunjuk untuk memperoleh manfaat dari peruntukkan harta benda wakaf sesuai pernyataan kehendak waqif yang dituangkan dalam Akta Ikrar Wakaf. Akta Ikrar Wakaf atau bisa disingkat AIW adalah bukti pernyataan kehendak waqif untuk mewakafkan harta benda miliknya guna dikelola nazhir sesuai dengan peruntukan harta benda wakaf yang dituangkan dalam bentuk akta. Nazhir merupakan pihak yang mengelola dana wakaf. Adapun pihak nazhir bisa dilakukan oleh perseorangan, organisasi, atau badan hukum.

Dana wakaf tunai dalam penelitian ini dihimpun oleh Lembaga Amil Zakat yaitu Baitul Maal Hidayatullah. UU RI Nomor 23 tahun 2011 pasal 1 menyebutkan
Lembaga Amil Zakat yang selanjutnya disingkat LAZ adalah lembaga yang dibentuk masyarakat yang memiliki tugas membantu pengumpulan, pendistribusian, dan pendayagunaan zakat. Kegiatan LAZ adalah mengumpulkan, mendistribusikan, mendayagunakan dana zakat ataupun wakaf tunai dari masyarakat

\section{METODE PENELITIAN}

\section{Pendekatan Penelitian}

Penelitian ini termasuk penelitian kualitatif, oleh karena itu data yang menjadi sumber penelitian tidak berbentuk angka, melainkan berupa hasil ucapan atau tulisan dan perilaku orang orang yang diamati.

"Pendekatan kualitatif adalah pendekatan dengan menggunakan data yang berupa kalimat tertulis atau lisan, peristiwa-peristiwa, pengetahuan atau proyek studi yang bersifat deskriptif" (Yin 2013:2).

Penelitian ini bertujuan untuk mencari jawaban atas pertanyaan: "Bagaimana pengelolaan dan pemafaatan dana wakaf tunai di Baitul Maal Hidayatullah Surabaya?". Metode yang digunakan dalam penelitian ini adalah studi kasus deskriptif yang bertujuan untuk menjelaskan dan menggambarkan dampak dari pengelolaan dan pemanfaatan dana wakaf tunai di Baitul Maal Hidayatullah Surabaya. Menurut Yin (2013:1) studi kasus merupakan suatu metode kajian empiris yang berusaha untuk menyelidiki fenomena kehidupan nyata dengan konteks tidak jelas dengan menggunakan berbagai sumber data 
Afdhal, et al/Jurnal Ekonomi Syariah Teori dan Terapan Vol. 3 No. 6 Juni 2016: 490-503; PROSES KEGIATAN PENGHIMPUNAN DAN DISTRIBUSI WAKAF TUNAI DI BAITUL MAAL HIDAYATULLAH SURABAYA

dengan menggunakan berbagai bentuk data kualitatif.

\section{Ruang Lingkup Penelitian}

Penelitian yang dimaksud adalah untuk menjawab rumusan masalah yaitu bagaimana pengelolaan dan pemanfaatan dana wakaf tunai di Baitul Maal Hidayatullah (BMH) Surabaya. Rumusan masalah tersebut menjadi acuan peneliti dalam menentukan ruang lingkup penelitian ini. Ruang lingkup penelitian ini terbatas pada cara lembaga amil dalam mengelola wakaf tunai dan cara yang dilakukan Baitul Maal Hidayatullah dalam memanfaatkan wakaf tunai. Kemudian data yang digunakan adalah data - data internal BMH khusus dalam hal dana wakaf tunai dan observasi kepada informan yaitu dari internal $\mathrm{BMH}$ dan waqif dari $\mathrm{BMH}$ Surabaya

\section{Sumber dan Jenis Data}

Data yang terdapat di penelitian kualitatif dibagi menjadi dua, yaitu data utama dan data tambahan. Data utama merupakan data primer yang berasal dari hasil observasi langsung ke lapangan ataupun hasil wawancara langsung terhadap pihak Baitul Maal Hidayatullah Surabaya dan donatur Baitul Maal Hidayatullah. Wawancara dilakukan pada kepala cabang dan pihak yang terkait dengan wakaf tunai Data tambahan merupakan data sekunder yang diperoleh dari suatu objek penelitian yang berupa dokumen, arsip-arsip, maupun laporanlaporan yang relevan serta kajian pustaka yang berkaitan dengan obyek permasalahan. Peneliti memakai teknik purposive sampling dalam menentukan informan untuk penelitian.

\section{Unit Analisis}

Penentuan unit analisis ini penting agar peneliti tidak salah dalam mengambil pengumpulan data dan pengambilan kesimpulan nantinya. Unit analisis dalam penelitian ini adalah penghimpunan dan pendistribusian dana wakaf tunai Baitul Maal Hidayatullah Surabaya.

\section{Prosedur Pengumpulan Data}

Langkah langkah yang dilakukan dalam prosedur pengumpulan data adalah sebagai berikut :

1. Persiapan awal

Persiapan awal mengurus surat izin penelitian secara formal pada bagian akademik Fakultas Ekonomi dan Bisnin Universitas Airlangga untuk dapat mewancarai pihak Baitul Maal Hidayatullah.

2. Proses memasuki obyek penelitian Menemui informan sesuai dengan janji yang telah dibuat sebelumnya, dengan membawa surat ijin penelitian secara formal dari Fakultas Ekonomi dan Bisnis Universitas Airlangga.

3. Di Lokasi atau obyek Penelitian

Maksud dan tujuan penelitian dijelaskan kepada informan kemudian melakukan obesrvasi secara langsung. Setelah itu dilakukan wawancara, Waktu pelaksanaan wawancara tergantung pada kesepakatan yang telah dibuat antara peneliti dan 
Afdhal, et al/Jurnal Ekonomi Syariah Teori dan Terapan Vol. 3 No. 6 Juni 2016: 490-503; PROSES KEGIATAN PENGHIMPUNAN DAN DISTRIBUSI WAKAF TUNAI DI BAITUL MAAL HIDAYATULLAH SURABAYA

Lembaga Amil Zakat Baitul Maal Hidayatullah.

4. Proses pengumpulan data

Peneliti ketika melakukan wawancara kepada objek penelitian akan mencatat dan merekam semua informasi yang diperlukan kemudian hasil wawancara tersebut akan dianalisis sehingga dapat dijadikan hasil pembahasan dan simpulan dalam penelitian ini.

Data sekunder diperoleh dengan prosedur sebagai berikut :

1. Kajian pustaka dan literatur yang berhubungan dengan wakaf tunai, cara pengelolaan wakaf tunai dan pemanfaatan wakaf tunai, yang diperoleh dengan cara membeli di toko buku yang berada di Surabaya, membaca buku di perpustakaan dan ruang baca Universitas Airlangga, dan informasi lainnya diperoleh melalui internet;

2. Mengikuti perkembangan terkini tentang wakaf ataupun wakaf tunai melalui koran dan televisi.

\section{Teknik Keabsahan Data}

Teknik keabsahan data yang digunakan dalam penelitian ini adalah teknik triangulasi. Teknik triangulasi menurut Yin (2013:38) merupakan sebuah teknik pemeriksaan keabsahan data yang memanfaatkan sesuatu yang lain di luar data untuk keperluan pengecekan atau pembanding terhadap data itu.

Triangulasi yang digunakan dalam penelitian ini adalah triangulasi teori dengan cara membandingkan dan mengecek sebuah hasil data yang diperoleh dengan teori yang ada. Dalam peneltian ini triangulasi teori dilakukan dengan cara membandingkan hasil wawancara dari pihak internal Baitul Maal Hidayatullah dengan teori - teori yang sudah dijelaskan dalam bab dua.

\section{Teknik Analisis}

Penelitian ini menggunakan teknik analisis penjodohan pola. Menurut Yin (2013:140) penjodohan pola adalah membandingkan pola yang didasarkan atas empiri dengan pola yang diprediksikan. Dalam studi kasus yang menggunakan metode deskriptif, penjodohan pola akan relevan dengan pola variabel variabel spesifik yang di prediksi dan ditentukan sebelum pengumpulan datanya.

\section{HASIL dan PEMBAHASAN}

Wakaf tunai di BMH cabang Surabaya dilakukan penghimpunan dana dengan seksama dimana dibuat laporan harian untuk dana wakaf tunai yang masuk melalui donatur yang datang langsung ke kantor BMH atau donatur yang membayar melalui nomor rekening bank atas nama Baitul Maal Hidayatullah. Dana wakaf tunai yang terkumpul itu nantinya akan disalurkan untuk pembangunan Pesantren Tahfidz Quran Yatim dan Dhuafa Darul Hijrah II.

Metode penghimpunan dana wakaf tunai yang dilakukan BMH dilakukan dengan metode langsung dan metode tidak langsung, metode langsung 
Afdhal, et al/Jurnal Ekonomi Syariah Teori dan Terapan Vol. 3 No. 6 Juni 2016: 490-503; PROSES KEGIATAN PENGHIMPUNAN DAN DISTRIBUSI WAKAF TUNAI DI BAITUL MAAL HIDAYATULLAH SURABAYA

dilakukan saat waqif datang langsung ke kantor cabang BMH Surabaya untuk membayar wakaf tunai, sementara metode tidak langsung saat waqif membayar donasi wakaf tunai melalui nomor rekening bank atas nama Baitul Maal Hidayatullah.

Masyarakat yang ingin membayar wakaf tunai ke BMH cabang Surabaya bisa memilih satu diantara dua cara yaitu yang pertama calon donatur bisa langsung datang ke kantor cabang $\mathrm{BMH}$ Surabaya yang berada di Jl. Mulyosari no.398 atau yang kedua bisa menghubungi nomor telepon di 0315928866 dan setelah itu bisa disepakati apakah donatur membayar ke rekening BMH Surabaya atau petugas BMH yang datang kerumah donatur untuk mengambil dana wakaf tunai tersebut.

Unsur - unsur penghimpunan dana wakaf tunai dilakukan BMH berupa analisa kebutuhan, identifikasi profil waqif, produk, serta harga biaya transaksi. Dibawah ini masing - masing penjelasannya sesuai yang dilakukan BMH Surabaya:

a. Analisa Kebutuhan

BMH melakukan laporan dan pertanggung jawaban atas dana yang dihimpun, laporan keuangan $\mathrm{BMH}$ dicantumkan dalam tabloid Mulia yang rutin tiap bulan dicetak. Untuk produk wakaf tunai yang ada di BMH nantinya akan disalurkan untuk memberikan manfaat bagi kesejahteraan umat dan kesejahteraan ini dalam bentuk peningkatan pendidikan berupa pembangunan Pesantren Tahfidz Quran dan Yatim Dhuafa Darul Hijrah II. Pelayanan yang berkualitas serta membangun silaturahmi dan komunikasi dengan waqif juga dlakukan oleh BMH.

b. Identifikasi Profil Waqif

Waqif yang melakukan donasi wakaf tunai di BMH akan dimintai keterangan tentang biodata diri yang meliputi nama, alamat dan nomor telepon yang bisa dihubungi oleh pihak BMH.

c. Produk

Produk wakaf tunai di BMH dibuatkan dalam bentuk program pendistribusian dana wakaf tunai yang meliputi pembangunan Pesantren Tahfidz Quran dan Yatim Dhuafa Darul Hijrah II, pembelian mobil ambulance, pembelian armada dakwah untuk da'i di pelosok, serta beasiswa untuk santri dari Pesantren Tahfidz Quran dan Yatim Dhuafa Darul Hijrah II. Walaupun dalam praktiknya BMH fokus untuk pembangunan Pesantren Tahfidz Quran dan Yatim Dhuafa Darul Hijrah II, sementara produk yang lain hanya dilakukan apabila waqif menginginkannya sesuai dengan akad yang disepakati di awal antara nazhir dan waqif.

d. Harga

Uang yang harus dikeluarkan oleh waqif untuk produk wakaf tunai di BMH beragam, mulai dari 250.000 rupiah hingga 50.000.000 rupiah. Untuk nominal yang harus dibayarkan waqif 
Afdhal, et al/Jurnal Ekonomi Syariah Teori dan Terapan Vol. 3 No. 6 Juni 2016: 490-503; PROSES KEGIATAN PENGHIMPUNAN DAN DISTRIBUSI WAKAF TUNAI DI BAITUL MAAL HIDAYATULLAH SURABAYA

dibuatkan BMH dalam bentuk paket donasi wakaf tunai. Beberapa paket donasi dibuat untuk memudahkan para waqif yang ingin membayar wakaf tunai di BMH Surabaya dan berikut tabel paket donasi wakaf tunai yang ada di Baitul Maal Hidayatullah Surabaya:

Tabel 1.

Paket Donasi Wakaf Tunai Baitul Maal Hidayatullah Cabang Surabaya

\begin{tabular}{|c|c|}
\hline Nama Paket & Jumlah \\
\hline Wakaf Tunai Firdaus & Rp.50.000.000 \\
\hline Wakaf Tunai Adn & Rp.25.000.000 \\
\hline Wakaf Tunai Na'iim & Rp. 15.000 .000 \\
\hline Wakaf Tunai Ma'wa & Rp. 10.000 .000 \\
\hline Wakaf Tunai Darussalam & Rp. 5.000 .000 \\
\hline $\begin{array}{c}\text { Wakaf Tunai Darul } \\
\text { Muqoomah }\end{array}$ & Rp. 1.000 .000 \\
\hline $\begin{array}{c}\text { Wakaf Tunai Maqoomul } \\
\text { Amiin }\end{array}$ & Rp. 500.000 \\
\hline Wakaf Tunai Khuldi & Rp. 250.000 \\
\hline
\end{tabular}

Sumber: Hasil Penelitian, 2016 (diolah)

BMH Surabaya memiliki alasan membuat paket donasi ini untuk wakaf tunai adalah karena bisa memudahkan calon waqif yang ingin membayar dan agar jelas berapa biaya yang harus dikeluarkan.

Untuk menarik minat masyarakat agar berdonasi wakaf tunai, BMH Surabaya memiliki beberapa cara, antara lain:

\section{Penerbitan Majalah}

Baitul Maal Hidayatullah mencetak majalah tiap bulannya, dan majalah ini bisa didapatkan oleh donatur BMH. Majalah yang bernama 'Mulia' ini berisi informasi seputar produk - produk yang ditawarkan $\mathrm{BMH}$, artikel yang memuat berita seputar Islam, hingga informasi kegiatan apa saja yang sudah dilakukan $\mathrm{BMH}$.

2. Promosi di Media Sosial

Dengan semakin majunya teknologi, $\mathrm{BMH}$ cabang Surabaya juga menjadikan teknologi sebagai salah satu cara menarik minat masyarakat untuk membayar wakaf tunai yakni melalui media sosial seperti Facebook dan Twitter. Di akun media sosial tersebut terdapat informasi seputar kegiatan $\mathrm{BMH}$ dan produk yang ada di $\mathrm{BMH}$ serta nomor telepon yang bisa dihubungi jika bersedia membayar wakaf tunai atau produk yang lain.

3. Melalui Pengajian

BMH cabang Surabaya sama halnya di cabang lain melakukan pengajian rutin tiap minggunya dengan tema yang menarik tentang Islam dan dari situ masyarakat akan semakin banyak yang mengetahui tentang $\mathrm{BMH}$ dan pada akhirnya bisa memberikan sebagian dananya untuk kepentingan umat melalui $\mathrm{BMH}$.

4. Penyebaran kotak infaq

Sering kita jumpai di beberapa restoran atau tempat umum lain terdapat kotak infaq yang disebar oleh BMH jika ingin menyumbangkan sebagian uangnya, jadi tidak perlu harus datang ke kantor cabang BMH. Cara seperti ini juga dapat mengenalkan $\mathrm{BMH}$ kepada masyarakat.

5. Door to door

Cara yang sebenarnya sederhana namun efektif adalah door to door, 
Afdhal, et al/Jurnal Ekonomi Syariah Teori dan Terapan Vol. 3 No. 6 Juni 2016: 490-503; PROSES KEGIATAN PENGHIMPUNAN DAN DISTRIBUSI WAKAF TUNAI DI BAITUL MAAL HIDAYATULLAH SURABAYA

BMH melakukan cara ini dengan tujuan menjalin silaturahmi dengan donatur dan bisa menerangkan secara langsung terkait produk yang ada.

Peneliti melakukan pengamatan langsung di BMH Surabaya saat ada donatur yang datang ke kantor $\mathrm{BMH}$ hendak membayar donasi, petugas BMH menanyakan terlebih dahulu akad apa yang ingin dilakukan, kemudian menjelaskan tentang program - program yang ada di BMH lalu setelah disepakati barulah akad bisa dilakukan dengan mencatat terlebih dahulu informasi tentang donatur seperti nama dan total donasi yang dikeluarkan.

Kentungan yang didapatkan bagi waqif yang membayar wakaf tunai di Baitul Maal Hidayatullah antara lain:

1. Investasi amal jariah dari wakaf memberikan kontribusi yang efektif bagi pembangunan generasi Qur/ani dengan pahala yang terus mengalir

2. Sertifikat bagi waqif

3. Kemudahan memperoleh layanan dakwah $\mathrm{BMH}$

4. Layanan ambulance gratis bagi keluarga muwaqif

Kendala atau kesulitan tentu dihadapi BMH dalam penghimpunan dana wakaf tunai seperti kurangnya pemahaman donatur terkait wakaf tunai.

Baitul Maal Hidayatullah cabang Surabaya dalam mendistribusikan dana wakaf tunai fokus untuk membangun Pesantren Tahfidz Quran Yatim dan Dhuafa Darul Hijrah II setelah sebelumnya membangun Pondok Pesantren Muallaf
Tengger, Pondok Pesantren Tahfidz Quran Yatim \& Dhuafa Darul Hijrah I, dan Balai Latihan Kerja dan PPAS Center. Berbeda dengan lembaga sejenis yang membuat wakaf produktif dimana wakaf tunai yang diterima nantinya akan disalurkan kepada masyarakat untuk selanjutnya menjadi modal usaha, sementara BMH Surabaya memanfaatkan dana wakaf tunai untuk membangun sarana pendidikan.

Nazhir di BMH Surabaya juga merangkap sebagai amil, karena yang mengelola wakaf tunai adalah Lembaga Amil Zakat maka proporsi dana kelola untuk wakaf diambil dari dana amil. Mencampurkan dana wakaf dengan dana infak dilakukan BMH dan dalam laporan keuangan nanti akan ada masing - masing pos untuk dana wakaf dan dana infak.

Pesantren Penghafal Al-Quran Darul Hijrah sebagai salah satu lembaga pendidikan Islam di Indonesia yang merupakan program dari Baitul Maal Hidayatullah melalui dana wakaf tunai yang dihimpun dari donatur memiliki komitmen untuk melahirkan generasi muslim yang berkualitas dengan dibekali kemampuan ulumuddin, leadership, dan life skill. Proyek pembangunan pesantren Penghafal Al-Quran Darul Hijrah merupakan salah satu ikhtiar untuk menjawab kebutuhan fasilitas penunjang pendidikan bagi santri penghafal AlQuran. Visi dari Darul Hirah yaitu mencetak kader pemimpin yang hafidz dan faham 
Afdhal, et al/Jurnal Ekonomi Syariah Teori dan Terapan Vol. 3 No. 6 Juni 2016: 490-503; PROSES KEGIATAN PENGHIMPUNAN DAN DISTRIBUSI WAKAF TUNAI DI BAITUL MAAL HIDAYATULLAH SURABAYA

As Sunah. Sementara misi yang dilakukan untuk mencapai visi tadi antara lain:

1. Membangun potensi dasar anak didik berdasarkan Al-Quran dan As Sunah.

2. Memandu anak didik untuk menghafal Al-Quran.

3. Memberikan bekal dasar bahasa, ulumuddin, dan iptek.

4. Mentarbiyah anak didik untuk mengamalkan Islam dalam kehidupan sehari - hari.

Lokasi dari Pesantren Tahfidz Quran Yatim dan Dhuafa Darul Hijrah yang kedua ini berada di area proyek seluas $6000 \mathrm{~m}^{2} \mathrm{di}$ sekitar Taman Dayu, Desa Ketan Ireng, Kecamatan Prigen, Kabupaten Pasuruan, Jawa Timur. Untuk santrinya sendiri tidak ada kriteria khusus yang ditetapkan $\mathrm{BMH}$, hanya fokus kepada anak yatim dan dhuafa

Keterbatasan Penelitian

Keterbatasan penelitian terdapat pada pihak Baitul Maal Hidayatullah yakni General Manajer Perwakilan yang tidak bisa diwawancarai secara mendalam tentang pengelolaan dan pemanfaatan wakaf tunai. Hasil wawancara dalam penelitian ini banyak mendapatkan jawaban dari Manajer Kevangan dan Kantor Baitul Maal Hidayatullah. Peneliti juga tidak meneliti langsung ke Pesantren Tahfidz Quran \& Yatim Dhuafa Darul Hijrah II sebagai program pemanfaatan wakaf tunai Baitul Maal Hidayatullah sehingga tidak mengetahui kemajuan proses pembangunan yang sedang berjalan apakah sesuai dengan anggaran yang sudah dibuat.

\section{SIMPULAN}

Berdasarkan hasil pembahasan di bab sebelumnya, dapat diketahui bahwa pengelolaan dana wakaf tunai di Baitul Maal Hidayatullah Surabaya dilakukan perhitungan dana secara harian, Penghimpunan dana wakaf tunai dilakukan secara benar berdasarkan ketentuan Islam, yaitu tidak mencampurkan antara dana halal dengan dana non halal yang dihimpun dari Baitul Maal Hidayatullah, dalam praktiknya penghimpunan dana wakaf tunai memakai metode langsung dan tidak langsung. Penghimpunan dana tersebut juga sesuai dengan Badan Wakaf Indonesia yaitu memiliki beberapa unsur penghimpunan dana, antara lain analisa kebutuhan, identifikasi profil waqif, produk dan harga biaya transaksi

Pendistribusian dana wakaf tunai yang dilakukan $\mathrm{BMH}$ sesuai dengan yang dijelaskan oleh Direktorat Pemberdayaan Wakaf yaitu menyalurkan dana wakaf tunai untuk bidang pendidikan dan bidang pelayanan sosial. Pendistribusian dana wakaf tunai yang fokus disalurkan untuk pembangunan Pesantren Tahfidz Quran dan Yatim Dhuafa Darul Hijrah II menyebabkan dana wakaf tunai langsung habis, dan untuk hak nazhir diambilkan dari dana infak dan dana zakat, karena nazhir di BMH juga merangkap sebagai amil maka hal tersebut bisa dilakukan. Dalam praktiknya 
Afdhal, et al/Jurnal Ekonomi Syariah Teori dan Terapan Vol. 3 No. 6 Juni 2016: 490-503; PROSES KEGIATAN PENGHIMPUNAN DAN DISTRIBUSI WAKAF TUNAI DI BAITUL MAAL HIDAYATULLAH SURABAYA

BMH belum melakukan penyaluran dana wakaf tunai untuk bidang pengembangan Usaha Kecil dan Menengah (UKM). Pelayanan dan penyampaian program yang dilakukan BMH kepada waqif sudah jelas sementara pemahaman waqif tentang wakaf tunai masih sebatas hanya pengertian wakaf tunai secara umum.

\section{DAFTAR PUSTAKA}

Aditya, Elma Muncar. 2008. Universalitas Ekonomi Islam. Fokus Ekonomi, Vol. 3, No. 1 (Juni) 2008

Al-Qur'an dan Terjemahannya. 2010. Syamil Al Qur'an. Bandung: PT. Sygma Azizy, Qodri. 2004. Membangun Fondasi Ekonomi Umat. Yogyakarta:Pustaka Pelajar

Direktorat Pemberdayaan Wakaf. 2006. Strategi Pengembangan Wakaf Tunai di Indonesia. Jakarta: Depag RI

Ghazaly, Abdul Rahman, et al. 2010. Fiqh Muamalat. Edisi Pertama. Jakarta: Kencana

Hidayat, Mohamad. 2010. An Introduction to The Sharia Economic. Jakarta:Zikrul Hakim

Katsir, Ibnu. 2001. Tafsir Ibnu Katsir. Jakarta:Pustaka Imam asy-Syafi'i

Majelis Ulama Indonesia (MUI), Fatwa tentang Wakaf Uang, 11 Mei 2002. http://www.mui.or.id diakses pada 7 Januari 2015 pukul 12.00 WIB

Nasution, Mustafa Edwin. 2005. Wakaf Tunai Inovasi Finansial Islam, Peluang dan Tantangan dalam Mewujudkan Kesejahteraan Umat. Jakarta: PKTTI-UI Norton, Michael. 2002. Menggalang Dana. Jakarta: Yayasan Obor Indonesia Dan Kemitraan Untuk Perubahan Tata Pemerintahan Di Indonesia

Wiroso. 2005. Penghimpunan Dana Dan Distribusi Hasil Usaha Bank Syariah. Jakarta: PT.Grasindo

Yin, Robert. 2013. Studi Kasus Desain dan Metode.Jakarta: PT Raja Grafndo Persada

Zulkifli, Sunarto. 2003. Panduan Praktis Transaksi Perbankan Syariah. Jakarta:Zikrul Hikam 